\title{
Impact Test Analysis of the Aging Property of Power Plant Running Silicone Rubber Insulators in the Fog and Haze Days
}

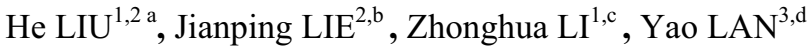 \\ ${ }^{1}$ Key Laboratory of Engineering Dielectrics and Its Application Ministry of Education for Harbin \\ University of Science and Technology, China \\ ${ }^{2}$ Electric Power Research Institute of Jilin Electric Power Co. of State Grid, China \\ ${ }^{3}$ Northeast Electric Power Design Institute Co.LTD, China \\ aliuhehe1984@163.com, b13180808385@163.com, ${ }^{\mathrm{c}}$ fgwjnpghaerbin@163.com, \\ d191428614@qq.com
}

\begin{abstract}
The current fog and haze days are increasingly serious. The pollution level in various regions of our country is increasing. With all kinds of dust and acid gas pollution in the fog and haze weather, the polluted surface of the silicone rubber insulators is slowly and evenly damp aging in the open operation. Here, the aging degree of the silicone rubber insulators which ran for different years under actual fog and haze environment has been analyzed, such as surface topography, hydrophilic/hydrophobic, thermal performance, mechanical properties and so on.
\end{abstract}

\section{Introduction}

Exhaust gas, smoke and dust (fine particles) of the industry, transportation and life discharge into the low altitude atmosphere to form haze and fog condensation nuclei.[1-2] Suspended fog droplets appear at the same time, hinders the diffusion of waste gas and dust. After the absorption of $\mathrm{SO}_{2}, \mathrm{NO}_{\mathrm{x}}$ soluble in water, the severe fog and haze weather forms. The current fog and haze days are increasingly serious. The pollution level in various regions of our country is increasing year by year. With all kinds of dust and acid gas pollution in the fog and haze weather, the polluted surface of the silicone rubber insulators is slowly and evenly damp aging in the open operation.[3] Fog conductivity increase and insulation reduction can cause numerous external insulation fault of electrical equipment, bring uncertain influence to the safe operation of power grid, and hamper the reliable performance of power system.[4] At present, the power system has a little understanding and estimation of the impact of the electric insulator safety operation in the fog and haze weather, especially

* Corresponding author:liuhehe1984@163.com 
the fouling and pollution flashover characteristics of the insulators in a large range of continuous fog and haze.[5-8] Therefore, in order to ensure the reliable power supply of the power grid in the area of bad fog and haze weather, it is one of the burning issues to research and analyze the contamination aging properties of the insulator in the fog and haze environment. From the new point of view of material chemistry, we analyzes the different kinds of test and analysis (such as surface topography, hydrophilic/hydrophobic, thermal performance, mechanical properties and so on) to study the aging properties of the silicone rubber insulators, which have been running under the condition of the actual fog and haze for different years.

\section{Results and Discussion}

In this paper, five sets of silicone rubber insulators are selected, which have been used 4 , $6,8,10$ years in power plants within a certain region and the new factory with same quality, respectively. Correspondingly, the $4 \#, 6 \#, 8 \#, 10 \#$ and N\# are tagged as the test sample. The surface contact angle of the insulator is measured, and the change of the surface properties is investigated. The contact angle photo of 10\#, 6\# and N\# is showed in Fig.1. The contact angle value of the 10\#, 8\#, 6\#, 4\# and $\mathrm{N \#} \mathrm{electrical}$ insulator is depicted in Table1, respectively. The results show that hydrophobicity of the hydrophobic silicone rubber insulators decreases gradually with the increase of the running year (from $137.4^{\circ}$ to $101.2^{\circ}$ ), as well as the increased pollution level.

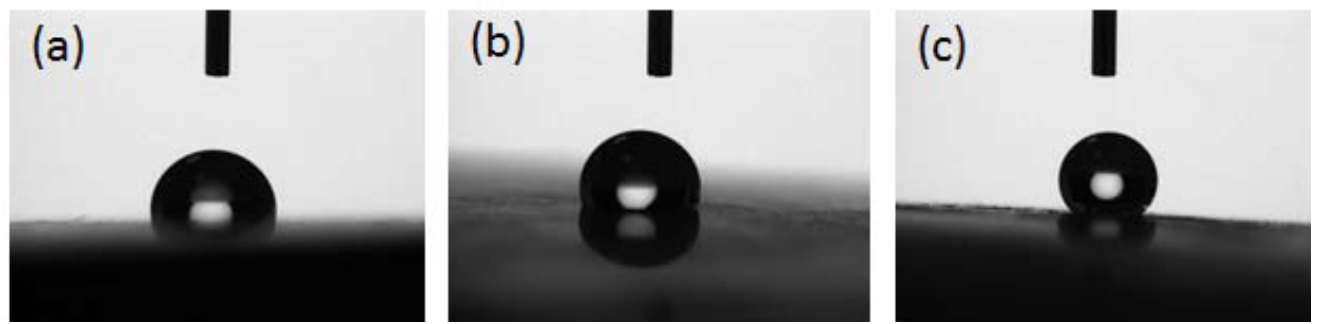

Fig.1. (a), (b), and (c) is the contact angle photo of the 10\#, 6\# and N\# electrical insulator, respectively. Table 1 . the contact angle value of the $10 \#, 8 \#, 6 \#, 4 \#$ and $n \#$ electrical insulator, respecitvely.

\begin{tabular}{|c|c|c|c|c|c|}
\hline serial number & $10 \#$ & $8 \#$ & $6 \#$ & $4 \#$ & N\# \\
\hline angle $\left(^{\circ}\right)$ & 101.2 & 107.9 & 113.8 & 120.5 & 137.4 \\
\hline
\end{tabular}

The microstructure of the insulator surface is characterized by an optical microscope, as shown in Fig.2. The surface of running 10 years of insulator is totally covered with dirt, with deep surface cracks. Along with the decrease of the running year, surface crack of the insulator clearly displays the trend of reducing, and the degree of pollution is gradually decreased. Surface of the running 4 years of the insulator is not found obvious cracks, the surface of which exhibits much less pollution.
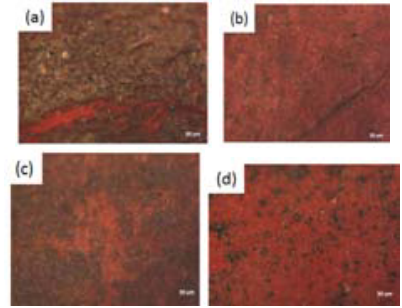

Fig.2. (a), (b), (c) and (d) is the microscope image of the 10\#, 8\#, 6\# and 4\# electrical insulator, respecitvely. The scale is $50 \mu \mathrm{m}$. 
Meanwhile, the mechanical properties of silicone rubber insulators in fog and haze are characterized by using a universal material testing machine. The mechanical properties such as tensile strength at break, modulus of elasticity in tension, tensile strain at break and yield strength at yield of the five sets of parallel silicone rubber insulators are tested, as displayed in Table2. As can be seen from the table, although operation time of the insulators is different, the inner-structure of the silicone rubber material is relatively stable. The mechanical behavior changes little. Besides, the tensile strength and yield strength values of the insulators are consistent.

Table2. the tensile strength at break, modulus of elasticity in tension and tensile strain at break of the $10 \#, 8 \#, 6 \#$ and 4\# electrical insulator, respecitvely.

\begin{tabular}{|c|c|c|c|c|}
\hline $\begin{array}{c}\text { serial } \\
\text { number }\end{array}$ & $\begin{array}{c}\text { tensile } \\
\text { strength at } \\
\text { break (MPa) }\end{array}$ & $\begin{array}{c}\text { modulus of } \\
\text { elasticity in } \\
\text { tension (MPa) }\end{array}$ & $\begin{array}{c}\text { tensile strain at } \\
\text { break (\%) }\end{array}$ & $\begin{array}{c}\text { tensile } \\
\text { strength at } \\
\text { yield (MPa) }\end{array}$ \\
\hline $10 \#$ & 3.28324 & 3.26161 & 117.46121 & 3.28324 \\
\hline $8 \#$ & 2.96837 & 4.64774 & 88.83989 & 2.96837 \\
\hline $6 \#$ & 2.56511 & 4.55588 & 107.14697 & 2.56511 \\
\hline $4 \#$ & 2.53584 & 3.39325 & 101.54595 & 2.53584 \\
\hline $\mathrm{N} \#$ & 5.40441 & 4.77989 & 132.01856 & 5.40441 \\
\hline
\end{tabular}

In addition, the two-dimension size to the change of temperature of the five groups of the silicone rubber insulators is measured, in the case of a certain temperature program, with load force close to zero. The temperature changing region of the insulator is simulated the outdoor environmental temperature limit range, $-40^{\circ} \mathrm{C} \sim 50^{\circ} \mathrm{C}$. he thermal expansion coefficient of the silicone insulator in the low temperature and the high temperature region is in an order of magnitude, that is, $10^{-4} / \mathrm{K}$. It is in accordance with the thermal behavior of the rubber material. It demonstrates that the thermal expansion of the interior silicone rubber material is relatively stable, after a long period of fog and haze. Both the mechanical properties and the thermal performance analysis indicate that the interior rubber properties of the insulators that run for many years still keep stably.

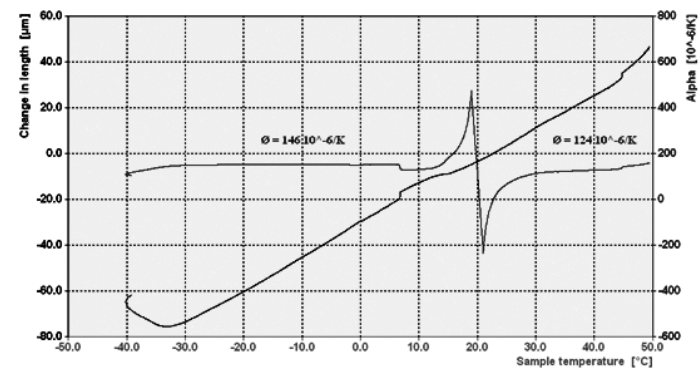

Fig.3.The thermal expansion curve of the $6 \#$ electrical insulator.

\section{Summary}

In this paper, the surficial (surface morphology and hydrophilic/hydrophobic) and internal (thermal and mechanical) properties of the silicone insulators with different running time, under the actual fog and haze environment are tested and analyzed. The aging degree of 
composite silicone rubber insulators is relatively stable. Yet, with the increase of the fog and haze, the surface pollution damage is obvious, hydrophobic property and insulation is decreased unavoidably, and the risk of electrical insulation failure is increased dramatically. It should be investigated and studied more detailed and exacted to elevate the operation safety of the power system.

\section{References}

1. J. van der Geer, J.A.J. Hanraads, R.A. Lupton, The art of writing a scientific article, J. Sci. Commun. 163 (2000) 51-59.

2. Pan Benfeng, Wang Wei, Li Liang, et al. The haze pollution characteristics and cause analysis in autumn and winter of large and medium-sized city in China[J]. Environment and Sustainable Development. 1 (2013) 33-36.

3. Yu Xingna, Li Xinmei. Optical properties of aerosols during haze weather in Beijing[J]. Environmental Science. 33 (2012) 1057-1062.

4. Wang Shaohua, Hu Wentang, He Wenlin, et al. Experimental research on pollution flashover voltage and leakage current characteristics of naturally polluted insulators[J]. Power System Technology. 37 (2013), 2855-2860.

5. Su Zhiyi, Li Qingfeng. Historical review and summary on measures against pollution flashover occurred in power grids in China[J]. Power System Technology. 34 (2010), 124-130.

6. Kumagai S, Yoshimura N. Hydrophobic transfer of RTV silicone rubber aged in single and multiple environmental stresses and the behavior of LMW silicone fluid[J]. IEEE Trans on Power Delivery. 18 (2003), 506-516.

7. Zhang Wei, Liang Xidong, Li Zhenyu, et al. Research on the test method of silicone rubber's hydrophobicity transfer and loss property[J]. Power System Technology. 30 (2006), 116-119.

8. Zhang Hui, Tu Youping. Study on aging characteristics of silicone rubber sheds of composite insulators based on TSC test[J]. Proceedings of the CSEE. 32 (2012), 169-174.

9. Shen Wenwei, Song Wei. Influence of corona discharge on aging characteristics of HTV silicone rubber material[J]. High Voltage Apparatus. 49 (2013), 1-7. 